\title{
When the Customer Isn't Right: How Unsupportive Donor Demands Lead to Ineffective NGO Practices
}

\author{
By Daniel Walker
}

Recent literature has criticized nongovernmental organizations (NGOs) and their activities on three main grounds: (1) NGOs incur higher-than-necessary overhead costs, (2) NGOs do not coordinate to distribute activities and projects according to beneficiary needs, and (3) NGO evaluation methods and results are biased. To discover the source of these inefficiencies, I interviewed the leaders of 34 NGOs in Kampala, Uganda. Based on trends in their responses, I argue that supposed NGO inefficiencies are actually logical reactions to strategies NGO donors employ. First, because donor financial commitments are sporadic, NGOs prioritize organizational spending, causing overheads to be higher than expected. Second, a lack of donor agreement on local needs leads NGOs to adopt client-specific objectives, leading to a lack of needs-based NGO project distribution. Third, because donors prioritize positive information in the short-term, NGOs have large incentives to deliver exclusive and/or biased data.

For a start, I don't think we-the NGO sector-are principled enough to give a damn about what someone will evaluate about [a] project, as long as they have the money.

- $\mathrm{CEO}$ of anonymous NGO, Kampala, Uganda

\section{Introduction}

In recent literature studying non-governmental organizations (NGOs), authors criticize NGO operations as being ineffective on several grounds. I deal with three of these criticisms in this article: (1) a tendency for NGOs to incur high overhead costs, (2) a lack of NGO coordination, and (3) ineffective NGO evaluations. In an attempt to discover the source of these inefficiencies, I conducted 34 interviews with NGO directors, CEOs, field workers, and country representatives in Kampala, Uganda. ${ }^{1}$ I find that most NGOs are efficient, but their interactions with other development actors often skew their incentives. Of the three ineffective NGO practices I study, I find that all three originate with the actions of NGO donors.

In interviews, NGOs characterized their interactions with donors as an economic market where donors are "clients" and NGOs provide certain "goods and services." Based on this model, NGOs trace most of their strategic decisions to "consumer-" or donor-based preferences. In this sense, alleged ineffective NGO practices actually ensure NGO longevity. That is, they are strategies for NGO survival. Issues arise when the overall goals of development are not aligned

1. All interviews were conducted in confidentiality, and the names of interviewees are withheld by mutual agreement. 
with NGOs' incentive to ensure their own survival. In this article, I show how inadequate and unproductive donor practices lead directly to what may appear to be ineffective NGO strategies.

These relationships have several broader impacts. For example, adverse NGO-donor relationships may help explain the "micro-macro paradox," by which macro-level development does not progress as quickly as micro-level development (Mosley 1986; Barder 2009). Some may incorrectly assume that what donors are "buying" at the micro level is correlated to macro-level development indicators such as GDP growth. According to my interviews, this is probably not the case. It appears that what donors commission has little to do with the quality or sustainability of NGO activities and more to do with project completion and selfpromotion. Thus, if donor strategies prove to be inadequate, development may only be an indirect result of many donor-NGO partnerships.

I proceed in four sections. The next section discusses the main theories of this paper and incorporates the relevant supporting literature. The third section reviews the interviewing methods, setting, and data. The fourth section analyzes the interviews and ties them back to the theories the second section describes. Lastly, the fifth section concludes with a summary of findings and suggestions for moving forward.

\section{Theory and Literature}

Studies of development aid tend to judge NGOs based on results while ignoring market structure and context. Most development literature has sought to assess NGOs based on assumed development objectivese.g., more schools, more literacy, more welfare, more health-instead of on how effectively NGOs accomplish the mandates of their clients, aid donors (Banerjee 2007; Miguel and Kremer 2004; Duflo 2004). Additionally, many authors view NGO activities from a political standpoint-i.e., from the basis that NGOs fill in gaps of local and national governments-instead of treating development as its own distinct economic market (Edwards et al. 1999). Recently, authors recognize an increased need for studies that observe an NGO "market" where NGOs produce "services" for donors instead of project beneficiaries (Burger and Owen 2010; Fruttero and Varun Gauri 2013). This approach is encouraged as far back in the literature as 1987 in an article that argues that NGOs should be classified based on their economic strategies (Hansmann 1987).

Viewing the NGO sector as a market helps to track incentives and particularly to show how some NGO strategies-often viewed as harmful to development objectives-are actually logical responses to inadequacies in NGO-donor relationships. This article aligns with the premise that the NGO sector is a market where NGOs are the "producers" of a service and donors are the "consumers."

When NGO-donor relationships are at their best, donors reward NGOs that provide services tied to long-term development objectives such as social or political change. There are several characteristics of donor operations, however, that reward other types of behavior, particularly, "short-term ... easily measurable and quantifiable results" (Ebrahim 2003, 817). Donors' emphasis on immediate NGO "products" may incentivize NGOs to focus on quantity rather than quality - the pressure to quickly deliver tangible products, such as sanitation facilities or school materials, may leave NGOs little time to ensure high product quality or sustainability. 
Additionally, donors focused on the short-term are, "unlikely to engender organizational learning since they encourage NGOs to exaggerate successes, while discouraging them from revealing and closely scrutinizing their mistakes" (818). Since emphasis is set on the speedy delivery of products, long-term organizational growth is not being encouraged or rewarded.

Focusing on measurable results is not a malign practice in itself. Indeed, progress would not be able to be tracked at all if not for the operationalization of development outcomes. However, development is a long-term endeavor, and NGOs will be unable to achieve development if donors do not prioritize it correctly in their demands. Unfortunately, the majority of donors are, "unable or unwilling to support... long time horizons" and thus tend to partner with NGOs only temporarily, sometimes for only one project at a time (Edwards and Hulme 1996, 11). Because of the tendency toward shortterm partnerships, there is little sense of long-term progress or even longterm consequences in the market. At the same time, the improvement of organizations themselves and the best operationalizations of development depend largely on what donors like to "consume" and what their long-term plans for the market as a whole might be.

\section{NGO Funding Allocation Decisions}

There is rife disagreement between donors and NGOs about funding allocation (Fruttero and Gauri 2005; Ebrahim 2003). NGOs are often faulted for, "[prioritizing] pragmatic, [organizational] concerns" instead of maximizing the funds allocated to service delivery (Fruttero and Gauri 2005,760 ). In fact, this stereotype is so pervasive that many participants in the NGO market, including rat- ing groups, directly associate low overheads with NGO effectiveness (Schimmelpfennig 2012).

Even when NGOs and donors agree on development objectives, uncertainty can cause NGOs to bias their financial decisions toward the stability of their own organizations, particularly through overheads. As the sheer number of NGOs has increased, competition for funding has also intensified. And, "with the renewal of funding becoming less secure... NGOs may become more risk adverse and allocate aid strategically" (Dreher et al. 2007, 7). Along with the fact that the majority of donors rarely stay with the same NGO for long periods of time, this creates a volatile funding horizon. Thus, to ensure their own survival, NGOs may invest a higher proportion of donor funds in their own organizations in the short term. These links between donor demands and NGO strategies are summarized in the figure below.

$$
\begin{aligned}
& \text { Figure 1: Sporadic donor funding } \rightarrow \\
& \text { Uncertain funding horizon } \rightarrow \text { More } \\
& \text { organizational spending by NGOs }
\end{aligned}
$$

\section{NGO Coordination Strategies}

NGOs do not have a sense of the plans, objectives, or strategies of other NGOs in the market, leading to frequent project overlap and repetition (Johnson and Prakash 2006; Edwards et al. 1999). Issues with duplicating work can be exacerbated when donors themselves do not coordinate. Although NGOs may be familiar with each other and work in the same overall sector, they do not have the same clients and thus work to achieve different, client-specific outcomes. While this lack of shared knowledge does not necessarily hurt the efforts of any one organization, it makes widespread development initiatives diffi- 
cult to organize and coordinate.

When combined with the

funding uncertainty described above, a lack of overall development progress among NGOs creates strong incentives for them to, "locate where other donors are engaged as well" (Dreher et al. 2007, 7). This is known as NGO clustering, a phenomenon in which NGOs converge to development "hot spots" instead of spreading activities based on beneficiary needs or requests. Additionally, NGOs have a strong incentive to adhere to client-specific goals to increase the likelihood of sustained funding. Both clustering and client-specific objectives translate to the unnecessary and disorganized concentration of aid, especially in geographic locations that are safer and more logistically convenient (Koch 2007; Dreher et al. 2007). Thus, NGOs trend toward donor allocation patterns instead of coordinating activities to fulfill widespread aims. These occurrences are shown in the chain below.

\section{Figure 2: A lack of donor coordina- tion $\rightarrow$ Client-specific NGO projects $\rightarrow$ NGO clustering $\rightarrow$ A lack of NGO coordination}

\section{NGO Information Provision \\ Lastly, there may be issues} with NGO operationalization, datagathering, and data-provision practices. Issues arise when NGO data are unique to a singular NGO-donor relationship to the extent that they are not comparable between organizations, even those within the same sector. The inability to compare development outcomes or the quality of NGOs themselves leaves NGOs without a common language for evaluation or progress, further exacerbating the scarcity of NGO collaboration. Incomparability also leads to high start-up costs with each new project since new data will likely have to be gathered independently and tailored to each specific initiative (Thomas 2010; Burger and Owens 2010). This process of unique data-gathering relates directly to the problem of client-specific projects discussed above: because many NGOs are satisfying the goals of individual clients, their data-gathering and evaluation techniques may also be client- or project-specific.

Combined with the will to survive, this situation can skew NGO incentives toward using data and evaluations for marketing instead of as a contribution to overall progress within a sector. While demonstrating aptitude and promoting achievements are not harmful practices in themselves, they can obstruct development in two main ways. First, they can, as I have mentioned, override initiatives that require collective involvement. Second, they can lead to information bias, even to the extent that NGOs may, "feel compelled to withhold the truth from the public eye in order to keep afloat" (Burger and Owens 2010, 1263).

Endeavors such as social change take considerable time and effort. I have discussed, however, that more immediate demands by donors may cause organizations to focus on short-term variables and measurements. Authors have explored this trend, noting that NGOs often only gather information in their evaluations that would be of interest to donor agencies (Thomas 2010; Bourguignon and Sundberg 2007). Also, as noted when discussing NGO clustering, organizations may choose ex ante to engage only in activities that produce more numerous measurements or that are popular topics internationally (Dreher et al. 2007; Desai and Yetman 2005).

Furthermore, these measure- 
ments are usually unique to a single project as opposed to fitting into a larger framework of progress within a sector. This is not to say that projectspecific evaluation and improvement is ineffective or unnecessary, but when combined with a lack of donor or NGO coordination, the results of these interventions and evaluations can have a very limited scope in terms of application or comparability to other initiatives. Often it is only within a single NGO-donor partnership that these data are meaningful and beneficial. The attributes of NGOdonor relationships that lead to this exclusivity of data and information are shown as links in the following chain.

Figure 3: Short-term information preferences $\rightarrow$ Focus on marketing and independent data-gathering $\rightarrow$ Biased and/or client-specific information

\section{Interview Methods}

To see firsthand whether the links of these chains held true in practice, I started at the nexus of development work: NGO leadership. In this section, I briefly describe my interview methods and the context in which I carried them out.

\section{Setting}

I conducted my interviews in Uganda's capital city, Kampala. Uganda's central location-bordering the Democratic Republic of the Congo, Rwanda, Tanzania, Kenya, and South Sudan-makes it a local hub for development organizations and initiatives. Uganda's recent government stability and economic growth contribute to its popularity as an NGO hotspot, allowing for a progress-oriented, foreigner-friendly environment.

Although Ugandan develop- ment workers are spread throughout the country, most NGO headquarters and main offices are located in Kampala. Thus, most administrative officials were located in the city, making it an ideal location to conduct my interviews since I desired most to speak with the individuals who had frequently interfaced with donors and who had a greater perspective on overall NGO operations.

With the help of the Uganda National NGO Forum and the Development Network of Indigenous Voluntary Associations (DENIVA), other helpful individuals, and simple street-contacting on my own, I conducted 34 interviews in six weeks. I also conducted several follow-up interviews.

\section{Target Group}

As mentioned, my target interviewees were NGO administrators such as CEOs, country directors, and department heads. I desired this perspective for two reasons. First, NGO administrators are almost exclusively individuals who have been working with NGOs for a long time, sometimes for their entire careers. This gives them more firsthand experience than others in the market and also means that they have witnessed the most sizable changes and developments (including the most prominent inefficiencies) in the market.

I also wanted the perspective of NGO administrators because my hypotheses are intimately tied to that level of NGO activity-administration. As I have discussed, my theories stem from the interaction of donors and NGOs, from NGO evaluation techniques, and from general NGO market characteristics. All of the activities associated with these initiatives are planned and coordinated at the administrative level. Thus, the directors of each NGO I visited gave 
me the most detailed and up-to-date information.

\section{Methods}

My interviews were largely open-ended, but I structured each one around the same topics-relationships with donors, evaluation techniques, and NGO market characteristics. Most interviews lasted between 40 and 60 minutes, with the first few interviews being longer and exploratory in nature.

My first round of questions dealt with NGO-donor relations. NGOs usually receive grant money from several different donors simultaneously and NGOs are frequently collaborating with new donors. Thus, experiences and opinions abound surrounding the topic of NGO-donor relations. As such, I was concerned that NGO opinions would be too diverse so as to find any consensus. However, the opposite was actually true. Even with a diverse and relatively large sample of organizations representing an even larger and more diverse sample of donors, opinions were remarkably similar, and I was able to recognize certain trends almost immediately.

To approach this topic, I began with some general questions about the NGO's current donor relationships-i.e., "How many donors do you have currently?" or, "Are there any donors that you've worked with more frequently?" I then proceeded with questions such as, "What type of donor makes you feel most comfortable?" or, "What donor attributes help you to be the most effective?" From there, I would proceed more conversationally with follow-up responses like, "Tell me more about [attribute]" or, "How does/would [attribute] help you to be more effective?" Other questions included, "What do you look for in a donor when applying for grants?" or, "What would you ideally like your relationship with your current donors to be like?"

I restricted my questions about evaluation techniques to NGO experiences. I did so because I was less interested in potential evaluation practices and much more interested in actual evaluation practices. Thus, I started with general questions such as, "Could you describe one of your recent projects and how the project was evaluated?" and then proceeded directly with follow-up responses. This allowed me to review the current techniques of project evaluation while also providing depth into a variety of actual evaluation examples.

The last topic, NGO market characteristics, was a bit more ambiguous and difficult to approach directly. Thus, most of the answers here arose from descriptions provided for the other two topics. I did, however, ask a few questions directly such as, "Do you collaborate with other NGOs in your same focus area? How often?" or "How do you determine where or when you will start a project?" I then proceeded with follow-up questions in order to reveal a larger view of the NGO market as a whole. Some other questions I used to approach this topic dealt with project overlap- "Do you often find yourself overlapping with other organizations on projects or initiatives?" - or with donor location decisions-" ten do donors determine the location of a project?" These direct questions, along with the general characteristics revealed through answers to questions in the first two topics, allowed me to determine if there were certain inefficient trends within the Ugandan NGO market.

\section{Transcription and Coding \\ Coding was relatively simple} due to the nature of the interviews. 
I coded in stages with the first stage being simply to identify relevant responses within subject areas of interest. The next stage was to break up these topics into smaller subtopics in order to organize NGO responses more specifically. For NGO-donor relations, I looked for comments regarding ideal donor attributes, policies for NGO-donor interaction, and experiences with grant-writing and approval. For evaluation techniques, I looked for comments on how NGOs evaluated projects and initiatives before, during, and after their implementation. For NGO market characteristics, I looked for comments about NGO collaboration, project overlap, and project location determination.

For the last stage, I separated each topic and subtopic into different documents. I then went through each of these documents individually and highlighted similar trends. For example, when coding the NGOdonor relations topic, I noticed that the word "flexible" appeared in several responses. Thus, responses with this word or idea were coded as one trend. I then grouped trends from each topic and compared these to my hypotheses. It is on these comparisons that I have based this paper and its conclusions.

\section{Results and Analysis}

I now turn to a discussion of the interviews themselves. In this section, I share and analyze excerpts from a variety of organizations according to the trends I have described above. The analysis provides an evaluation of the causal chains I have outlined.

\section{NGO Funding Allocation Decisions In the second section, I men- tion that NGOs worry about sporadic donor funding and that this can lead to more organizational spending.}

With the quotations below, I provide evidence that these are indeed characteristics of NGO-donor relationships.

I first look at evidence for sporadic funding and uncertainty. The following quotations express this concern in two main ways: first, as annoyance and frustration with the practice of donors emphasizing project-based initiatives instead of program-based partnerships, and second, as a discussion of the necessity for constant fundraising and grantwriting. I start here with project vs. program based funding.

The other thing which I think should be understood about donor money and NGO work is whoever brought the three-year project was an enemy of development because a three-year project fits in the life of the average politician, it doesn't fit in the life of the context.

Most donors are project based. We would prefer if they were program based because with the project based, what they come and say is that we are going to pay thoroughly for the staff on the project with us.

So, for me, it's getting out of [a project-based] mentality and the donors should know that there are projects they need to commit to long-term.

We need to recognize that development cannot be boxed into three years. Development must be built in a long-term agenda, a holistic national agenda.

The ideal donor, we would want someone who takes time with us. [That] is the ideal because you would get the impact. With ad- 
vocacy work that change doesn't come there and then. So [an ideal donor] would be the person who is taking time with you.

The NGOs quoted here express frustration with short-term projects that do not have consistent objectives. One even notes that three-year projects are an "enemy to development," thus passionately sustaining the idea that short-term uncertainty is detrimental to development outcomes. NGOs also speak about procuring funds as a signal for uncertainty in the following quotes.

Ya, I think we are limited in our knowledgeability about the available foundations or donors. [As] it were, the reason why $X$ is able to carry out the activities that it has planned is because it has a strategic plan that is fully funded rather than having a project-based funding.

We respond to a lot of proposals. We write proposals that we know. The thing which we have seen in funding is that they give a person, they know that kind of thing. So we write a lot of proposals and submit but one or two go through.

Whenever there is one listed that is within our area of intervention, we apply. So it's an ongoing application process. And it can take, well we just got approval of one that we put in two years ago and we just got approval now. The process is long, so fundraising for us is an ongoing activity.

Actually we wouldn't refuse to respond to any requests for funding, but the only thing that we have to get [it] cleared from our head office.
The constant need for fundraising and grant seeking supports the idea that funding uncertainty is common. The first quotation even provides a nice comparison with a larger organization (denoted anonymously as " $X$ ") that observes "full funding" vs. "project-based funding." Whereas the former is noted as affording the ability to "carry out [its] strategic plans," the latter leads to a "limited knowledgeability [of] available ... donors." Next I provide evidence that organizational spending concerns are also a common theme among NGOs. I start here with a quotation from a leading indigenous NGO dealing with rural energy issues.

[A donor] shouldn't look at only the projects alone. [They] should look at the totality of the whole organization and make a contribution for the executive director. And as I said, the institution like rent and those overheads.

This NGO mentions both "[contributions] for the executive director" and "overheads," such as rent, denoting the desire for donors to support organizational spending and development. This point of donor neglect of organizational concerns is reinforced by several more quotations.

Project-based funding is very specifically limited to the project and doesn't often increase the strength of the organization for the long term. So you build up staff for that project, when the project is done, the staff are gone. You buy equipment for that project, when it's done you have to hand it back to the donor or give it to your partners. So it's not as beneficial to the organization in terms of growth and development and sustainability. 
I think it would be very important for donors to start thinking about including salaries in the proposals; to allow organizations to have salaries within the proposals. You are finding that most organizations in Uganda are becoming more and more stunted because they get money once and after that you're on your own and you look for money and you can't get it.

Most organizations come and give them money, but all the finance and technical are centralized, so these people just implement and they don't have the capacity built.

But now, the best donor would be the one we can't get: the one who writes a blank check. The best donor is one who has balance and who builds capacity within you. And makes sure that even your system allows for your own improvement. Even for the organization. Something that allows you to have organizational development, capacity building.

So, again, we would like a donor to also understand if we ask in our proposal to put in a rent component. That is something that should be taken care of. Then, there are issues like the finance and administration office also the receptionist, even the CEO is on the support staff. In short, what I was trying to say is that a donor should look at all aspects in addition to the medical program staff.

In characterizing ideal donors, NGO quotes touch on the theme of organizational development through spending on overheads and capacity building. Although organizations are certainly concerned with organizational spending normally, this pattern's appearance in discussions of NGO-donor relationships supports the theory that there are specific concerns about organizational spending that are directly attributable to donors.

\section{NGO Clustering}

The next NGO practice that I discuss is NGO clustering. Clustering is brought about by client-specific NGO strategies and a lack of NGO coordination, and I provide evidence here of both of these phenomena. I start with a few quotations which discuss client-specific activities.

If you haven't built credibility you find that any donor will come anytime and say, "Now, we want you to do this," even if it is not exactly within your mandate or within what you are supposed to do.

We are just responding to [proposal requests] and trying to fit yourself, sometimes you are round trying to fit yourself in a square hole. But you have a strategic plan which says different things. For example, I might be interested in a type of development which is not getting funding. So you try to change even what you are passionate in.

I think we are finding a situation whereby a lot of the activities that are done are directed by the funder, which isn't necessarily the ideal situation.

So you have such situations where the funder is determining what you do which makes it a bit difficult.

You can't design. If you just sit 
and design, it will be thrown away because you need to have someone's priority areas.

Altogether we look at what does the donor want and how can we fit the project in properly?

These excerpts point out that although NGOs may know what interventions are needed on the ground they are often driven by consumer demand to converge to donor interests. One organization even notes having to "change ... what you are passionate in," demonstrating the strong pull of funding to unite with a specific client's demands.

Next I show NGO attitudes toward coordination. From these quotations, it is evident that little collaboration happens in the field.

In Uganda, it's a no-man's-land really: anybody can come and set up shop, do three years, and go away. [We are losing the war against AIDS] because of these sporadic interventions.

I cannot tell you in Kampala how many organizations are pursuing the issue of HIV / AIDS. Few have organized meetings between them.

So, yes I think [more partnership] would be beneficial, and I also think, not so much from an evaluation perspective, but from a coordination of funding and a coordination of activities. It's really difficult to know who is doing what, so if it was organized according to sector and then you could see who was doing what where and in what geographical region, it would be really helpful.

Ya, it would be extremely helpful because, when we go into a district for the first time, the best we get is the name of the organization and where it's located ... there's no one else who does it.

From [the perspective of] a coordination of funding and a coordination of activities, it's really difficult to know who is doing what.

The common theme here is a lack of knowledge of other organizations' undertakings or progress in the development market as a whole. This trend, combined with NGOs' clientspecific focus, supports the theory that the NGO market is not currently engaged in widespread coordination.

\section{NGO Information Provision \\ Lastly, my theories indicate} that NGO information provision may be biased and / or client-specific due to short-term information preferences and the need for marketing strategies. Here I show that short-term information preferences as well as strictly independent data-gathering methods exist in NGO-donor relationships. I start with quotations speaking to the point of short-term information preferences.

This is where sometimes I feel donors may need things which I feel are not very useful. [They] want numbers. And numbers reached. For us, most of our money is going into [radio dramas] and other materials which are not one-toone. Then you find you are running around looking for numbers, but meanwhile it is not the real thrust of your work.

Progressively though, I think money has shifted-once big money came in it started shifting the work of NGOs into more 
accountability to the donors than focusing on the quality of service delivery and accountability to the communities. [Donors] spend so much time looking at the risk and how to control the risk that in the end it focuses on undermining the quality of delivery.

Donors that want results quickly: we are talking here about social change, it's slow. We are talking about bumpy roads, about human beings who are starving or dealing everyday with finding food.

These quotations each describe pressures from donor agencies, even noting that short-term aims may "[undermine] service delivery." This pressure provides adequate incentive for NGOs to adhere to donor demands in order to stay in business. And in order to adhere to specific donor preferences, organizations may choose, as shown in the following quotation, data-gathering methods that are client- or project-specific.

So, we would want to see that the evaluation is specific to the project and what is being done within the project.

Project-specific evaluation itself is not a harmful issue-one would expect project improvement to be a vital element of NGO activities. However, the combination of this attribute with a lack of coordination can cause development exclusivity within locations and sectors. I show that such data independence exists in the following quotes which discuss data-gathering techniques.

We also usually do a baseline when we start a program to see what the situation is like, and then we use that to measure our progress. In terms of activities and evaluating whether people are actually learning something, we usually use pretests and post-tests, so before the activity starts we do a pretest, when it's done we use a post-test, and then we use the results to assess whether or not we're transferring knowledge.

This method-pre- and post-testingis a classic and effective procedure for individual project evaluation. The issue, however, is that the NGO that gave this quote mentions having to come up with the relevant measurements and methods for evaluation independently. This is reinforced by the following quotation:

We make indicators and everything. We develop it ourselves and then send it to them.... The initiation is ours.

These quotations come from two organizations that have been in Uganda for eight and 15 years, respectively, and yet they still have to develop new metrics and measurement plans for each new project. Neither organization cites the use of data from other NGOs. Furthermore, there is no mention of adherence to or even the existence of sector-wide standards for their operations. These next quotations show that independent operationalization and data-gathering activities are also common among other NGOs.

At the inception, we also do a baseline survey based on some key indicators and then we do an end-of-project evaluation, but in between we do mini-assessments to see how far we are going in relationship to that.

So for each one, we must have a 
baseline, and that will collect from this research. And then we do [project assessments], the results from work, what you are supposed to achieve as an outcome.

We normally conduct a baseline survey. And the baseline surveys give us a benchmark of where we are starting. So when we are developing our monitoring and evaluation frameworks, we indicate those baselines where we are starting. And then we indicate how/when we would be monitoring.

[Also], every time we get into a new area, we do a baseline survey. Before we start on an initiative, we want to do what we call evidence based programming, so we begin by documenting a baseline survey about the existing situation before the intervention.

So, the form basically tries to see how many people we have reached-it's a simple tool that shows how many clients we have served, how many people came to our offices, and how many we targeted plus the networks we formed during the reporting period.

In one sense these quotations demonstrate the dedication and capacity of the organizations they represent, but they also relate back to the "no-man'sland" that is mentioned in the NGO clustering section because each organization seems to be an island of its own data-none of the organizations mention utilizing or producing data that also would be useable by other NGOs. In fact, when asked about publishing data along with evaluations, NGOs unanimously interpret this as an accountability or credibility mechanism as shown in these quotes.

Because they are many things being done, but when evaluations are done like this, it is primarily to serve the interests of the person who commissioned that evaluation. But also, it is going to improve your ability to attract elsewhere; then it becomes sensible.

The person that would be priority for me-that I would really want to see the results-is my next potential supporter.

Donors; even politicians [should see the results], which can be interesting for advocacy. ... It would show that we are a strong partner.

[It] always depends on the nature of the evaluation; most evaluations are just for the donor ... we definitely want to discuss results; otherwise, we don't know what the donor is looking for. $X$ [has] the results of all the evaluations of its projects ... and that's good; not just accountability, but also could help NGOs get out there more.

Of course we would want to shine and I know that if you publish, that gives the organization some prominence. So we don't mind our name coming out in the public, on the internet or anywhereit gives us help to have that donor confidence. An organization needs to have some credibility and that's what we are trying to build here.

$\mathrm{Ya}$, it is a good indicator because it sells the organization-that would be the best because they help in publicity. 
But I wouldn't mind being published positively.

Ya, because you need some sort of accountability, whether it's the public or your staff or, in this case, the NGO's donors.

Given the trends in client-specific strategies and incentives, it is understandable and perhaps even expected that NGOs would gravitate more toward accountability and credibility to stakeholders than to participating in overarching enterprises. This supports the theory that NGOs are regularly producing independent, client/ project-specific data that may be unintelligible to organizations outside of the project context. And this NGO isolation has other consequences, among them the possibility for information bias or withholding. Unfortunately I was not able to test this last possibility in my interviews. However, I did manage to get one related quotation in response to a question about reporting and accountability.

[We] are not principled enough and so ... [I] would probably just go for the grant. I would probably do some shoddy work, [but] I can always change my organization's name. Evaluation or not, [I] will go for it-even if it were going to be published. And [I] would probably cook up some success story somewhere.

This certainly does not represent a trend, but it does attest to the possibility of biased information being a problem in NGO operations. Further research in the vein of Burger and Owen's 2010 article could help to bring the prevalence and magnitude of this inclination to light.

\section{Summary}

My evaluation of each NGO activity and their proposed origins can be reviewed in Table 1 below.

Table 1: Evidence for Attributes of NGO-Donor Relationships

\begin{tabular}{|l|c|l|}
\hline \multicolumn{1}{|c|}{ Chain Links } & Evidence? & \multicolumn{1}{|c|}{ In What Way? } \\
\hline Sporadic donor funding & Yes & $\begin{array}{l}\text { NGOs mention short-term projects } \\
\text { and the need for continuous fund- } \\
\text { raising activities. } \\
\text { More organizational spending by } \\
\text { NGOs }\end{array}$ \\
\hline Client-specific NGO projects & Yes & $\begin{array}{l}\text { NGention capacity building } \\
\text { and organizational spending as } \\
\text { lacking in their relationships with } \\
\text { donors. }\end{array}$ \\
\hline Lack of NGO coordination & Yes & $\begin{array}{l}\text { NGOs note how donors often } \\
\text { require them to converge to donor } \\
\text { interests. } \\
\text { NGO partnering is infrequent and } \\
\text { NGOs have little idea of peer activi- } \\
\text { ties. }\end{array}$ \\
\hline Short-term information preferences & Yes & $\begin{array}{l}\text { NGOs note donor tendencies to } \\
\text { want immediate information. } \\
\text { NGOs describe independent data- } \\
\text { generating activities and associate } \\
\text { data dissemination with credibility } \\
\text { as opposed to collaboration. }\end{array}$ \\
\hline $\begin{array}{l}\text { Independent data-gathering and } \\
\text { marketing }\end{array}$ & Yes \\
\hline
\end{tabular}


I now turn to a final discussion of these results and some possible solutions to realign NGO incentives to advantage development outcomes.

\section{Conclusion}

There are several adverse characteristics of the NGO market that donor strategies perpetuate. I have provided evidence that shows that NGOs are likely to prioritize organizational concerns, are unlikely to coordinate their efforts, and are still collecting independent data that are client and context-specific. I have also shown how each of these behaviors stems from strategies employed by donor organizations.

Other authors and NGOs themselves have proposed solutions to these issues. Perhaps the most consistent viewpoint is that donor organizations should create more long-term relationships with NGOs to lower funding uncertainty and reduce incentives (and the ability) to bias communication. NGOs prefer "program" funding to "project" funding in order to reduce this uncertainty and increase accountability. Closer NGO-donor relationships would also benefit the areas of coordination and evaluation. Long-term initiatives could have broad goals toward which multiple parties could work to improve relationships, making evaluation more detailed and meaningful.

The idea of shared goals is important, and more donors are recognizing the need to collaborate in their funding choices. The Millennium Development Goals-a group of eight international development objectives that were established following the Millennium Summit of the United Nations in 2000 - is a good example of a series of broad goals for which donors can coordinate efforts. One of the goals, for example, is to achieve universal primary education by 2015 . Although a large undertaking, this goal provides a clear objective that donors can accept and collaborate to achieve. The goal also offers clear benchmarks by which all NGOs on the ground can be evaluated and have clearer ideas of methods, necessities, and expectations.

More informative ex-ante data on NGO quality could also help donors make better funding decisions and regulate unclear expectations of credibility. Here the idea of standardized evaluation principles could be helpful, especially since independent ex-ante data gathering could be a very expensive initiative for a donor with each potential partner. NGOs have already seen the need for this type of standardized evaluation mechanism. Two NGO networks I interviewed, in a rare collaboration with hundreds of member organizations, had already created a program called the NGO Quality Assurance Certification Mechanism (QuAM). This evaluation system was designed by NGOs to assess organizations on a variety of administrative, financial, and operational criteria. QuAM focuses on organizational quality and growth as opposed to project performance, but the program represents an important step toward the possibility of widespread, comparable standards. International development is making progress, but there are still important improvements to make, especially as so many new donors and NGOs continually enter the market. In order for this work to progress, both consumers and suppliers need more meaningful, long-term relationships in which collaboration is encouraged. Based on my interviews, NGOs recognize the need for these kinds of relationships and are making efforts to seek them out when working with new donors. This is an 


\section{References}

Barder, Owen. 2009. "What Is Poverty Reduction." Center for Global Development Working Paper 170:1-22.

Banerjee, Abhijit V. 2007. Making Aid Work. Cambridge, MA: MIT Press.

Bourguignon, Francois, and Mark Sundberg. 2007. "Aid Effectiveness: Opening the Black Box." American Economic Review 97(2):316-21.

Burger, Ronelle, and Trudy Owens. 2010. "Promoting Transparency in the NGO Sector: Examining the Availability and Reliability of Self-Reported Data." World Development 38(9):1263-77.

Desai, Mihir A., and Robert J. Yetman. 2005. Constraining Managers Without Owners: Governance of the Not-for-Profit Enterprise. No. w11140. National Bureau of Economic Research.

Dreher, Axel, Florian Mölders, and Peter Nunnenkamp. 2007. Are NGOs the Better Donors? A Case Study of Aid Allocation for Sweden. No. 1383. Kieler Arbeitspapiere.

Duflo, Esther. 2004. "Scaling Up and Evaluation." In Annual World Bank Conference on Development Economics, edited by François Bourguignon and Boris Pleskovic, 341-369. Washington, DC: The World Bank.

Ebrahim, Alnoor. 2003. "Accountability in practice: Mechanisms for NGOs." World Development 31(5):813-29.

Edwards, Michael, and David Hulme. 1996. "Too close for comfort? The impact of official aid on nongovernmental organizations." World development 24(6):961-73.

Edwards, Michael, David Hulme, and Tina Wallace. 1999. "NGOs in a Global Future: Marrying Local Delivery to Worldwide Leverage." Public Administration and Development 19(2):117-36.

Fruttero, Anna, and Varun Gauri. 2005. "The Strategic Choices of NGOs: Location Decisions in Rural Bangladesh." Journal of Development Studies 41(5):759-87.

Hansmann, Henry. 1987. "Economic Theories of Nonprofit Organization.” in The Non-Profit Sector: A Research Handbook, edited by Walter W. Powell and Richard Steinberg, 117-139. New Haven, CT: Yale University Press.

Johnson, Erica, and Aseem Prakash. 2007. "NGO Research Program: A Collective Action Perspective." Policy Sciences 40(3):221-40.

Koch, Dirk-Jan. 2007. "Blind Spots on the Map of Aid Allocations: Concentration and Complementarity of International NGO Aid." Research Paper No. 2007/45. http: / / www.wider.unu.edu/publications / working-papers / research-papers / 2007/ en_GB/rp2007-45/_ files / 78091842533657044/ default/ rp2007-45.pdf.

Miguel, Edward, and Michael Kremer. 2004. "Worms: Identifying Impacts on Education and Health in the Presence of Treatment Externalities." Econometrica 72(1):159-217.

Mosley, Paul. 1986. "Aid-Effectiveness: The Micro-Macro Paradox.” IDS bulletin 17(2):22-27.

Schimmelpfennig, Saundra. 2012. Lies, White Lies, and Accounting Practices: Why 
Nonprofit Overhead Doesn't Mean What You Think It Means. Portland, OR: The Charity Rater, LLC.

Thomas, Vinod. 2010. "Evaluation Systems, Ethics, and Development Evaluation." American Journal of Evaluation 31(4):540-48.

Danny Walker just finished a Master of Arts in Political Science at the University of Illinois Urbana-Champaign with an emphasis in comparative institutions and foreign aid. He is excited to apply this experience in the field of Public Policy, specifically within the topic of international development. His current work focuses on combining social science methods-such as matching analysis and crowdsourcing - with impact evaluation. To this end, he recently worked with several colleagues to publish a report on the impact of the United Nation's Peacebuilding Fund in Burundi. Even more recently, Danny worked with several partners and the United Nation's Children's Fund to develop and promote their new crowd sourcing initiative, U-Report, in addition to running a small field experiment on the usefulness of crowdsourced information to local government officials.

The author would like to thank the following individuals for their assistance and input: Mike Findley for helping to build this project and sending the author to Africa, Lauren Soelberg and Eric Darsow for assisting with interviews and transcriptions, Bonnie Mutungi and DENIVA for providing access to so many wonderful organizations, Megan Spencer for helping with follow-up research and analysis, and Jennifer Brinkerhoff, Anne Kruse, and Andrew Pike for dedicating so much of their time to editing and giving invaluable feedback. 